\title{
Thermodynamics of DNA Hybridization on Gold
}

\author{
Nanoparticles
}

\author{
Jun Xu and Stephen L. Craig* \\ Department of Chemistry and Center for Biologically Inspired Materials and Material Systems, Duke \\ University, Durham, NC 27708
}

\section{Thermodynamics of DNA hybridization}

As a DNA duplex solution is heated, the UV absorbance versus temperature provides a thermal melting curve. The stability of a DNA duplex is given by the melting temperature $T_{m}$, the temperature at which half of the duplexes have been melted to single strands. For short single strands at equal concentrations, $K_{e q}$ and $T_{m}$ are related to the total concentration of single strands $\left(C_{t}\right)$ by eq. S1 and S2: ${ }^{1}$

$$
\begin{aligned}
& 1 / T_{m}=\left(R / \Delta H^{\circ}\right) \ln \left(C_{t}\right)+\left(\Delta S^{\circ}-R \ln (4)\right) / \Delta H^{\circ} \\
& K_{e q}\left(T_{m}\right)=4 / C_{t}
\end{aligned}
$$

Note that, if the concentration of one single strand is in significant excess of that of the other one, $K_{e q}$ and $T_{m}$ are merely related to the concentration of the excess single strand ( $C_{e}$ in eq. $\mathrm{S} 3$ and $\left.\mathrm{S} 4\right)$ :

$$
\begin{aligned}
& 1 / T_{m}=\left(R / \Delta H^{\circ}\right) \ln \left(C_{e}\right)+\left(\Delta S^{\circ} / \Delta H^{0}\right) \\
& K_{e q}\left(T_{m}\right)=1 / C_{e}
\end{aligned}
$$

Therefore, DNA thermodynamics in solution and on gold surfaces can be extrapolated from the plots of $1 / T_{m}$ versus $\ln \left(C_{t}\right)$ and $1 / T_{m}$ versus $\ln \left(C_{e}\right)$, respectively. 


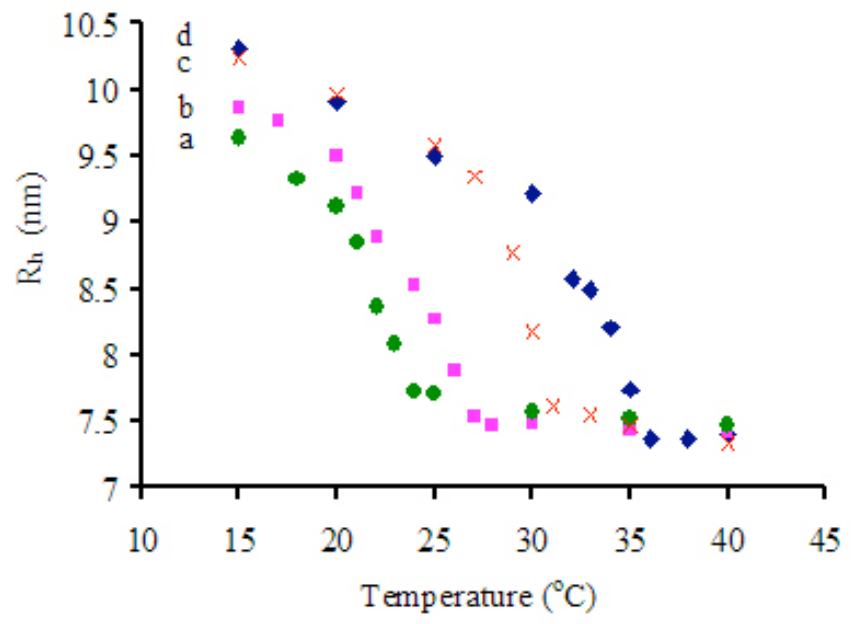

Figure S1. Hydrodynamic radius $\left(R_{h}\right)$ versus temperature from 15 to $40{ }^{\circ} \mathrm{C}$ for GC-1 (4 nM) with different concentrations of 4; a) $0.01 \mathrm{mM}$; b) $0.03 \mathrm{mM}$; c) $0.10 \mathrm{mM}$; d) $0.20 \mathrm{mM}$.
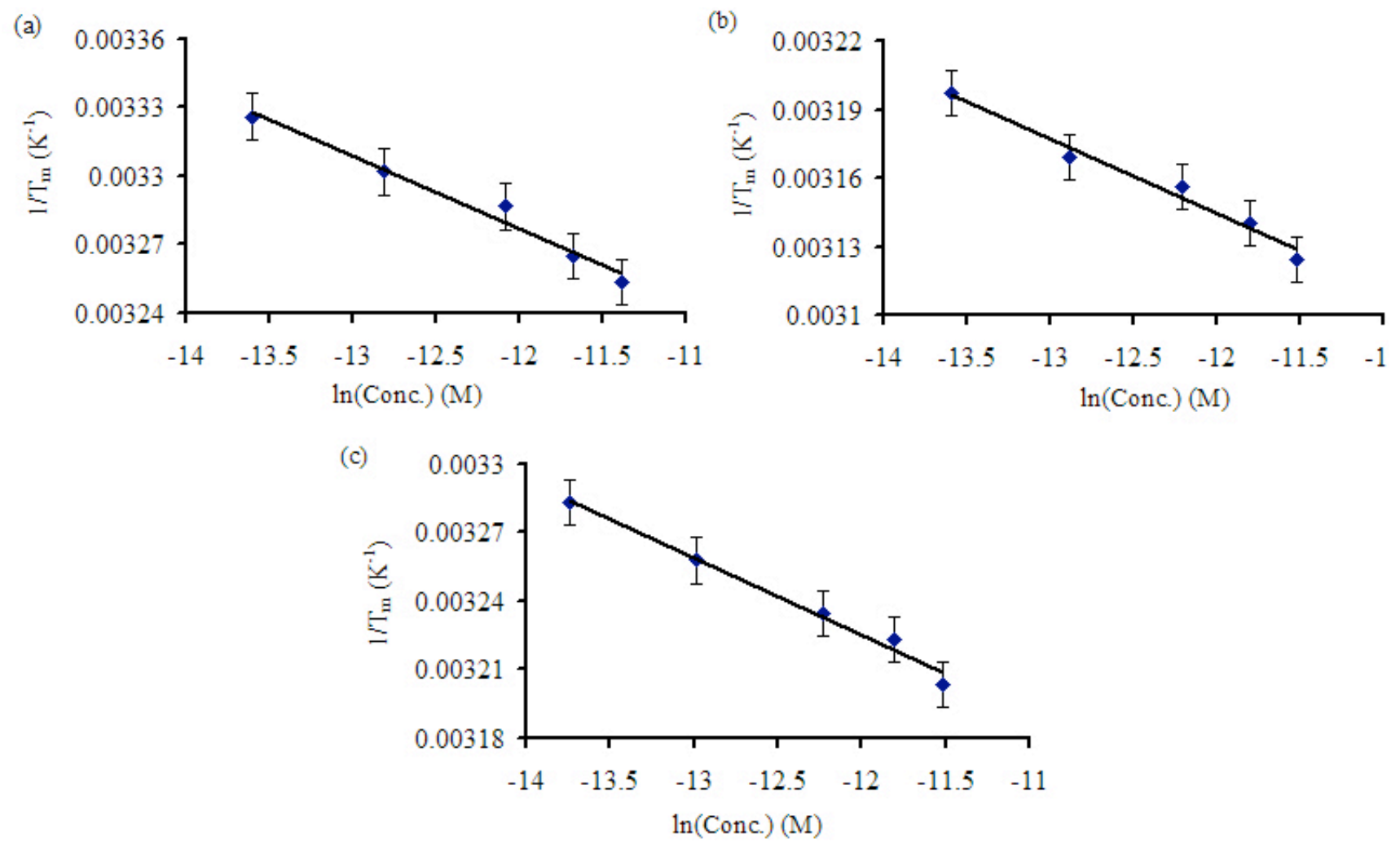

Figure S2. Melting temperature $T_{m}$ as a function of concentration in $0.3 \mathrm{M}$ PBS buffer, determined using UV-Vis spectrophotometry. a) GC-2 + 4; b) GC-2 + 5; c) GC-2 + 6 (see main text for base sequences). 

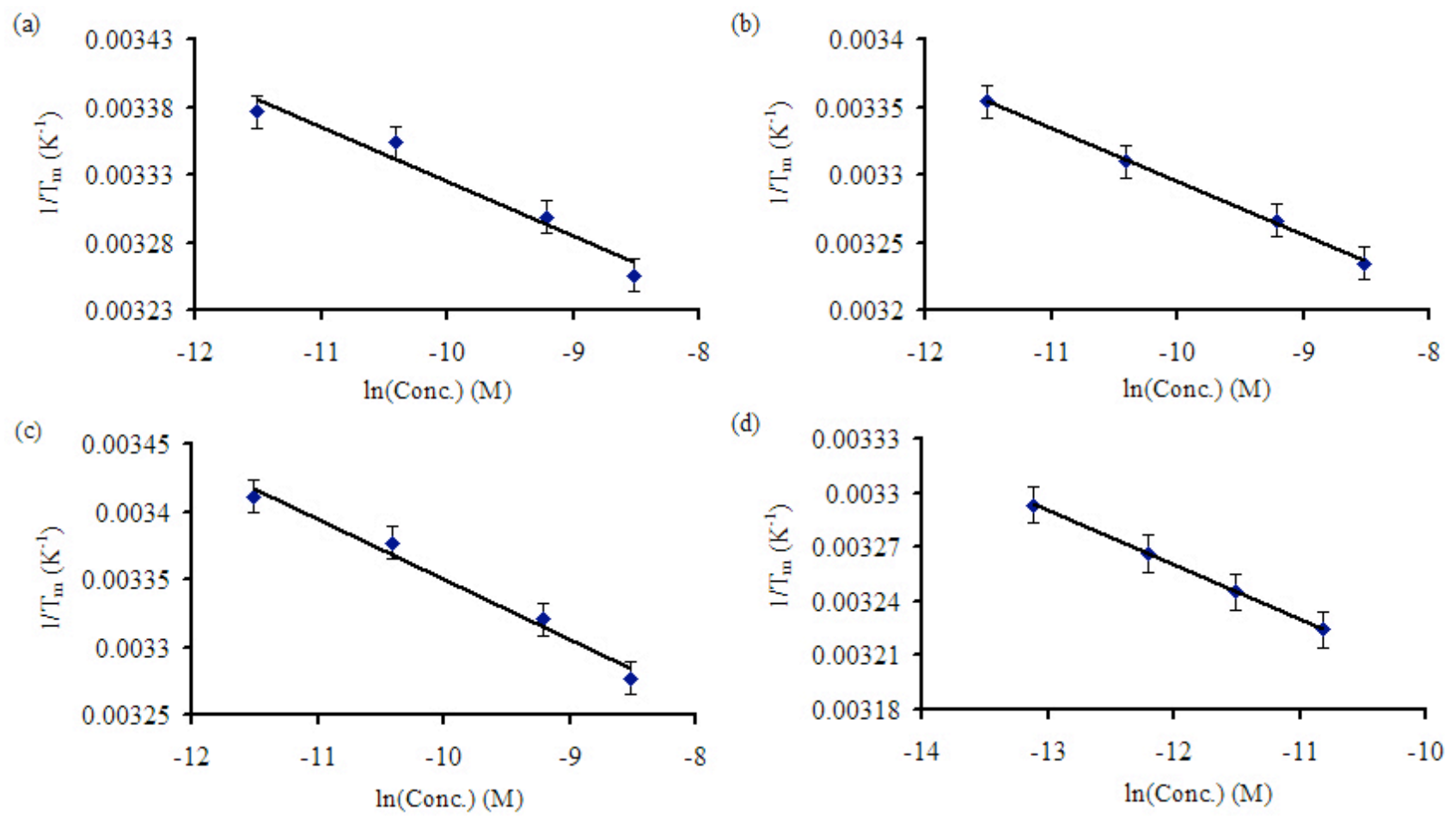

Figure S3. Melting temperature $T_{m}$ for duplexes on gold nanoparticles, measured by dynamic light scattering, as a function of solution concentration of target DNA. Here, $T_{m}$ is defined by the midpoint of the change in $R_{h}$. a) GC-2 +4 ; b) GC-2 +5 ; c) GC-2 +6 ; d) GC-3 +7 (see text for base sequences).

\section{Effect of laser light irradiation}

To determine whether the laser light irradiation affects the DLS measurement, the laser was turned off during the temperature equilibration, and then turned on immediately $(<10$ seconds $)$ before commencing data collection. No significant difference was found between either the appearance of the correlation function (Figure S4) or the measured values of $R_{h}$ at the beginning of data collection and those at the end (30 minutes), indicating that laser irradiation at the wavelength and powers used here does not make a significant contribution to the observed differences in thermodynamics. 

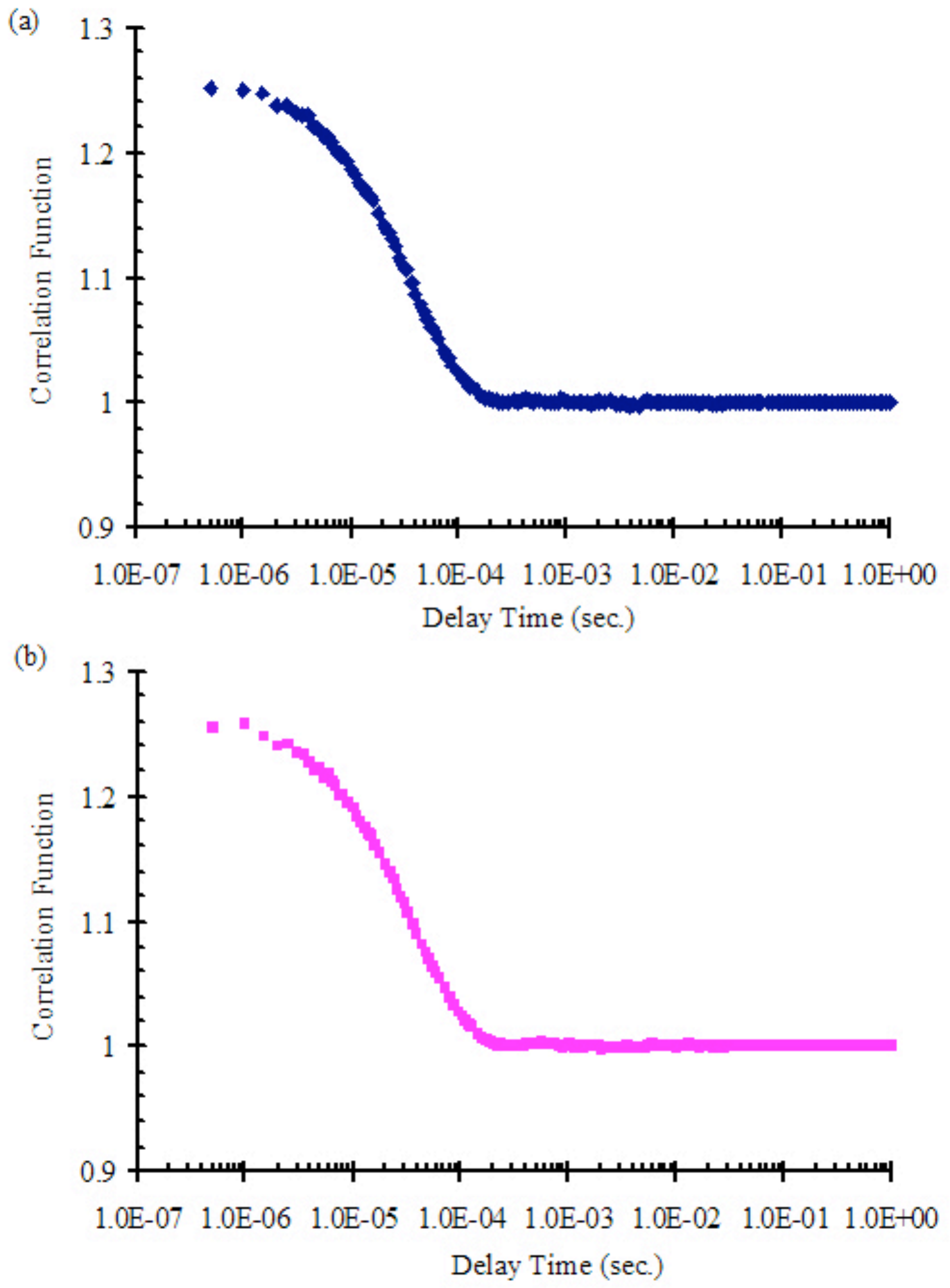

Figure S4. Comparison of QELS correlation function (a) immediately upon turning on the laser, and (b) at the end of 30 minutes laser irradiation. The excellent consistency between the two curves shows that heating during irradiation does not affect the measurements. 


\section{Thermal melting of DNA-induced gold nanoparticle aggregates}

Oligonucleotide 8 (5'-GGCTCTCT-SH-3') was purchased from Operon Biotechnologies. It was received as the disulfide and was reduced by solid phase DTT (Calbiochem Inc.), followed by desalting through Poly-Pack cartridges (Glen Research Corp.) prior to gold nanoparticle modification. Gold colloids (10 nm in diameter) were purchased from Ted Pella Inc. and used as received. GC-8, complementary in sequence to the 5 ' end of $\mathbf{4}$, was prepared according to the procedures in the text.

Gold nanoparticle aggregates were formed when GC-1, GC-8, and 4 were mixed and stored overnight (final concentration of GC-1, GC-8 and 4 is $1 \mathrm{nM}, 1 \mathrm{nM}$, and $0.1 \mathrm{mM}$, respectively). Thermal melting of gold nanoparticle aggregates was conducted on a Hewlett Packard 845x UV-Visible Spectrophotometer according to literature procedures. ${ }^{2}$ Briefly, the mixture was stirred and heated from $20{ }^{\circ} \mathrm{C}$ to $70{ }^{\circ} \mathrm{C}$ at $0.5{ }^{\circ} \mathrm{C} / \mathrm{min}$ and the absorbance was monitored at $520 \mathrm{~nm}$. The melting temperature of the aggregate was determined as $43.5^{\circ} \mathrm{C}$, while the melting temperature of GC-1 $(1 \mathrm{nM})+4(0.1 \mathrm{mM})$ in solution is $38.8{ }^{\circ} \mathrm{C}$. This result demonstrates that the aggregate stability is still enhanced by the additional cooperative bridging duplexes between nanoparticles, although the duplexes on the GC-1 surface are less stable than their counterparts in solution $\left(T_{m}=29.5^{\circ} \mathrm{C}\right.$ at $\left.0.1 \mathrm{mM} \mathrm{4}\right)$.

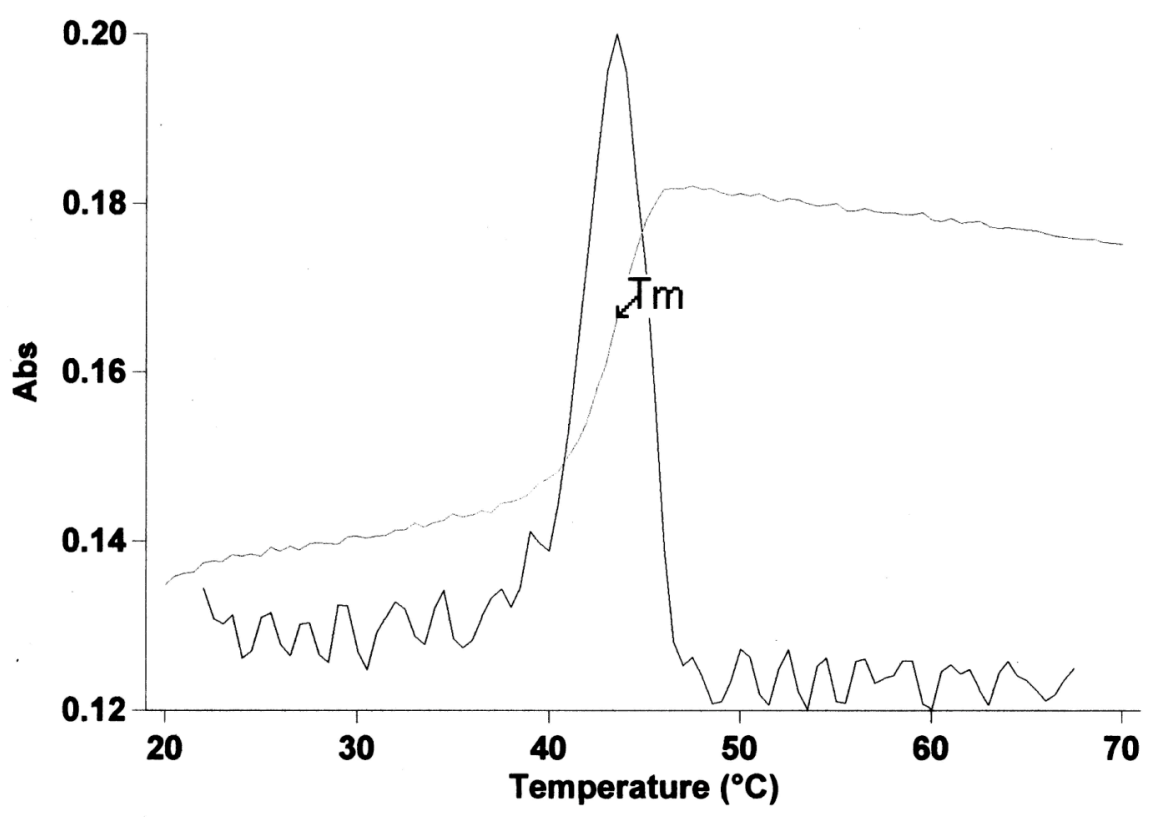

Figure S5. Thermal melting curve of gold nanoparticle aggregates formed by GC-1 + GC-8 $+\mathbf{4}$ (final concentration is $1 \mathrm{nM}, 1 \mathrm{nM}$, and $0.1 \mathrm{mM}$, respectively). 


\section{References}

(1) Plum, G. E.; Breslauer, K. J.; Roberts, R. W. Comprehensive Natural Products Chemistry 1999, 7, 15-53.

(2) Jin, R.; Wu, G.; Li, Z.; Mirkin, C. A.; Schatz, G. C. J. Am. Chem. Soc. 2003, 125, 1643-1654. 